\title{
Evaluation of Neuroprotective Effect of Sevoflurane in Acute Traumatic Brain Injury: An Experimental Study in Rats
}

\author{
Guvenc DOGAN ${ }^{1}$, Onur KARACA² \\ ${ }^{1}$ Hitit University School of Medicine, Department of Anesthesiology and Reanimation, Çorum, Turkey \\ ${ }^{2}$ Aksaray University Faculty of Medicine, Department of Anesthesiology and Reanimation, Aksaray, Turkey \\ Corresponding author: Guvenc DOGAN guvencdogan@gmail.com
}

\section{ABSTRACT}

AIM: To examine the effect of sevoflurane, a halogenated anesthetic used in clinical applications, on oxidative stress and inflammation after an acute traumatic brain injury (TBI) in rats.

MATERIAL and METHODS: Thirty male Sprague-Dawley rats were divided into three groups: control (Group 1), trauma (Group 2), and trauma+sevoflurane (Group 3). A diffuse TBI model was created for Groups 2 and 3. Sevoflurane anesthesia was applied 6 hours a day after induced trauma in Group 3. Glutathione (GSH), malondialdehyde (MDA), and tissue myeloperoxidase (MPO) activities were measured in the blood. Tumor necrosis factor alpha (TNF-a), vascular endothelial growth factor (VEGF), and Bax primary antibodies were used to determine the effects of TBI.

RESULTS: MDA was significantly higher in Group 2 than in Group 1. There was a significant increase in tissue MPO levels in Groups 2 and 3 compared with those in Group 1. GSH levels decreased in Groups 2 and 3. Group 3 revealed degenerative changes in neurons and glial cells, vascular enlargement and congestion, and inflammatory cell infiltration around blood vessels. In Group 3 , VEGF expression was positive in endothelial and inflammatory cells around blood vessels. Group 3 had positive TNF-a expression in neurons, small granular cells, and glial cells around blood vessels.

CONCLUSION: Sevoflurane administration in acute TBI did not prevent the development of oxidative stress and inflammation.

KEYWORDS: Traumatic brain injury, Sevoflurane, VEGF, BAX antibodies, Rat

\section{INTRODUCTION}

$\mathrm{T}$ Traumatic brain injury (TBI) leads to significant changes in brain structure and functions with different levels of severity. In the acute stage, it may cause tissue breakdown and destruction. Clinical presentation appears due to biomolecular and cellular changes following the initial injury $(9,32)$. After trauma, cerebral edema, neuroinflammation, and blood-brain barrier fragmentation occur. Once the bloodbrain barrier is corrupted, circulating leukocytes immediately invade the brain parenchyma and result in moderate-tosevere TBI. With the activation of transcriptional factors in the neurovascular cascade, these cells block the resident neuroinflammatory response $(8,18)$.
Oxidative stress after TBI begins with lipid peroxidation, largely attributed to a high content of poly unsaturated fatty acids in the brain. In a rat focal contusion model, lipid hydroperoxides were progressively accelerated immediately after trauma in the formation of hydroxyl radicals (11). Oxygen-free radicals released after TBI cause lipid peroxidation in cell membranes, which results in increased cellular malondialdehyde (MDA) content as well as glutathione (GSH) superoxide dehydrogenase and myeloperoxidase (MPO) activity. This biochemical chain induces cell damage.

Sevoflurane is a halogenated anesthetic used in clinical applications with rapid pharmacokinetic activity and low respiratory irritability. Sevoflurane can protect nerve functions in rats with ischemic brain injury and can significantly reduce 
the number of cerebral infarction areas and apoptotic cells. Studies have shown that pre-treatment with sevoflurane has a neuroprotective effect on mice exposed to brain ischemia (35).

VEGF is a regulator of pathological and physiological angiogenesis and vascular permeability. It also induces cell proliferation (15).

Tumor necrosis factor alpha (TNF-a) is a cell signaling protein found in systemic inflammation. The overproduction of TNF-a caused by TBI can be significantly attenuated by blocking TNF-a synthesis or activity (28). Many cell types such as microglia, astrocytes, endothelial cells, and neurons generate TNF- $a$ in the cerebrum. TNF- $a$ is involved in important cell events of apoptotic and necrotic cell death as well as cell growth and differentiation (21). Bax is a proapoptotic family member of $\mathrm{Bcl}-2$, which participates in cell death regulation. Bax is also a critical pathological finding explaining apoptosis without neuronal and glial cells. The effect of $\mathrm{TBI}$ on the regional cellular patterns of $\mathrm{Bcl}-2$ and $\mathrm{Bcl}-\mathrm{x} \mathrm{L}$, as well as the expression of survival-enhancing proteins, and extracellular signal is regulated. Kinase, Bax, c-Jun N-terminal kinase, tumor suppressor gene, tumor protein p53, and proteasecausing proteins such as the caspase family were investigated (25).

The aim of the present study was to investigate the effect of sevoflurane administrationon an acute TBI animal model by analyzing oxidative stress and inflammatory markers.

\section{MATERIAL and METHODS}

\section{Housing Animals and Protocol}

All procedures were performed according to the Guide for the Care and Use of Laboratory Animals. Local permission was obtained from the Ethics Committee for the Treatment of Experimental Animals (University of Health Sciences, Ankara Education and Research Hospital, Ankara, Turkey; No: 005115.02.2019). In total, 30 male Sprague-Dawley rats weighing averagely $260 \mathrm{~g}$ were housed in a room maintained at $25^{\circ} \mathrm{C}$ for 12-hour light/dark cycle. All animals were allowed to easily access standard pelleted food and water. Rats were randomly categorized in three groups: control (Group 1), trauma (Group 2 ), and trauma + sevoflurane (Group 3). A diffuse brain injury model defined by Marmarou et al. was used in this study (20). In brief, a trauma device drops a constant weight at a predetermined height through a tube. A 300-g weight dropped from a 1-m height has been shown to induce mild brain trauma by Ucar et al. (31). An acrylic box $(40 \times 40 \times 30 \mathrm{~cm})$ was used for sevoflurane experiment. All rats were placed in the box and exposed to 3\% sevoflurane using an evaporator (BS-400T; Brain Science Idea Co. Ltd., USA) for induction. After confirming anesthesia, rats were taken from the box and exposed to $1.5 \%$ sevoflurane using a rodent face mask. Sevoflurane concentration was calculated by confirming the loss of deafness reflex in rats. During anesthesia, rats were kept on a heating pad to hold an approximate core temperature of $37^{\circ} \mathrm{C}$. Body temperature of rats was constantly observed with a rectal probe. Sevoflurane anesthesia was applied for 6 hours a day after trauma. When sevoflurane anesthesia was stopped, it was adjusted according to the time of onset of the dark phase (34).

At the end of the $5^{\text {th }}$ day, blood samples were obtained from each animal and analyzed for inflammation and oxidative stress biochemical markers. After 5 days, $5 \mathrm{mg} /$ kg xylazine $\mathrm{HCl}$ (Rompun, Bayer Health Care AG, Germany) and $40 \mathrm{mg} / \mathrm{kg}$ ketamine $\mathrm{HCl}$ (Ketalar, Pfizer Inc., USA) were intraperitoneally injected in for euthanization. Then, choroid plexus of the lateral ventricles was rapidly dissected. Brain tissues were fixed in 10\% neutral buffered formaldehyde for histological examination. Tissues were dehydrated through a descending alcohol series and embedded in paraffin blocks. Haematoxylin-eosin was used for staining cerebral sections.

\section{MDA and GSH Peroxidase (GSH-Px) Assays}

MDA levels and GSH-Px activities of each brain tissues were evaluated with average values reported for each group. On ice, brain samples were homogenized with 10\% homogenate (according to weight) in $0.9 \%$ saline. The homogenate was then centrifuged at $2000 \mathrm{rpm}$ for $10 \mathrm{~min}$. Supernatant was transferred to another tube and diluted, and pellets were discarded. MDA levels were assessed by a double heating method reported by Draper and Hadley (6). Fatty acid peroxidation generates MDA as the end product, which reacts with thiobarbituric acid (TBA) and forms a colored complex. In brief, $2.5 \mathrm{~mL}$ TBA solution (100 g/L) was mixed with $0.5 \mathrm{~mL}$ homogenate in a centrifuge tube. After boiling in water for 15 minutes, these tubes were cooled down underflowing water. After centrifugation at $1000 \mathrm{rpm}$ for $10 \mathrm{~min}, 2 \mathrm{~mL}$ supernatant was mixed with $1 \mathrm{~mL}$ TBA solution $(6.7 \mathrm{~g} / \mathrm{L})$. These tubes were placed in boiling water for another $15 \mathrm{~min}$. After cooling, TBAreactive species concentration was measured at a wavelength of $532 \mathrm{~nm}$, and the MDA concentration was measured using the absorbance coefficient of the MDA-TBA complex. MDA values were expressed as nanomoles per gram $(\mathrm{nM} / \mathrm{g})$ of wet tissue.

The GSH-Px activity was measured by Paglia and Valentine method (24). An enzymatic reaction was initiated by the addition of hydrogen peroxide $\left(\mathrm{H}_{2} \mathrm{O}_{2}\right)$ to a tube containing reduced nicotinamide adenine dinucleotide phosphate, sodium azide, $\mathrm{GSH}$ reductase, and reduced GSH. Absorbance change was measured ata wavelength of $340 \mathrm{~nm}$ with spectrophotometry

\section{Tissue MPO Activity}

Tissues MPO activity was calculated using a protocol reported by Hillegas et al. (13). MPO activity is expressed as $\mathrm{U} / \mathrm{g}$ tissue.

\section{Evans Blue Assay for Blood-Brain Barrier Permeability}

The integrity of the blood-brain barrier was measured using Evans blue dye as a marker of albumin extravasation (2). Evans blue is expressed as $\mu \mathrm{g} / \mathrm{mg}$ of brain tissue referenced from a standard curve.

\section{Immunohistochemical Technique}

Tissues were fixed in $10 \%$ formalin solution, dehydrated through an ascending alcohol series, and embedded in paraffin wax for immunohistochemical analysis. Then, sections were incubated in xylene and washed with distilled water. Antigen 
retrieval was conducted twice (for 7 and 5 min, respectively) with an ethylenediaminetetraacetic acid buffer solution $(\mathrm{pH}$ 6.0 ) in a 700-W microwave oven. Samples were allowed to cool down at room temperature for $30 \mathrm{~min}$ and washed in $\mathrm{dH} 2 \mathrm{O}$ for $2 \times 5 \mathrm{~min}$. To block endogenous peroxidase, $0.1 \%$ $\mathrm{H}_{2} \mathrm{O}_{2}$ was applied to tissues for $20 \mathrm{~min}$. Ultra V block (Cat. No. 85-9043, Invitrogen, Carlsbad, California, USA) was used for 10 min before primary antibodies TNF-a (Cat. No. P300A, Invitrogen), VEGF antibody (Cat. No. PA3-067, Invitrogen), and Bax antibody (Cat. No. 33-6600, Invitrogen). Later, sections were incubated with secondary antibodies (Cat. No. 85-9043, Invitrogen) for $20 \mathrm{~min}$. Following 20-min exposure to streptavidin-peroxidase, diaminobenzidine (DAB, Cat. No. 34002, Invitrogen) was used as a chromogen. Control slides were treated with the same procedure, but phosphate-buffered saline was used instead of the primary antibodies. After counterstaining with hematoxylin and washing in tap water for $8 \mathrm{~min}$, sections were examined with a light microscope (5).

\section{Statistical Analysis}

SPSS (Version 22) was used for all statistical analyses. Mean \pm standard deviation (SD) was calculated for each group. Normality distribution of data was examined by Shapiro-Wilk test. One-way ANOVA tests were used to determine group differences with a $\mathrm{p}$-value of $<0.05$ indicating significance. Different groups were compared with post-hoc Bonferroni correction. The mean $\pm 2 \mathrm{SD}$ values of groups are shown in attached figures.

\section{RESULTS}

\section{Biochemical Analysis}

Groups 2 and 3 had significantly higher tissue MDA values than Group 1 ( $p<0.001$ and $p<0.001$, respectively; Figure 1$)$. Tissue MPO activity was significantly higher in Groups 2 and 3 than in Group $1(p<0.001$ and $p<0.001$, respectively; Figure 2). Groups 2 and 3 had significantly lower tissue GSH levels than group $1(p<0.001$ and $<0.001$, respectively; Figure 3). No significant differences were observed between Groups 2 and 3 in terms of MDA, MPO, and GSH activities $(p=1.000$, $p=1.000$, and $p=1.000$, respectively; Table I).

\section{Histopathological Findings}

Regarding Group 1, it was found that the cortical pyramidal neurons in the cerebrum were polyhedral with chromatin-rich nuclei. Glial cells were scattered far from each other, and their nuclei were small and round. In the cerebral cortex, neurons and glial cells were normal. Lumen and endothelial cells of cortical capillaries were regular (Figure 4A). In Group 2, degenerated pyramidal cells with pyknotic nuclei, dilated and congested blood vessels with hyperplasic endothelial cells, inflammatory cell infiltration around the vein with nuclear dissolution and neuronal vacuolar degeneration were observed (Figure 4B). Group 3 presented with degenerative changes in neurons and glial cells, vascular enlargement and congestion, and inflammatory cell infiltration around blood vessels. Pyknosis and apoptotic changes in the nuclei of pyramidal neurons and glial cell were also observed (Figure 4C).

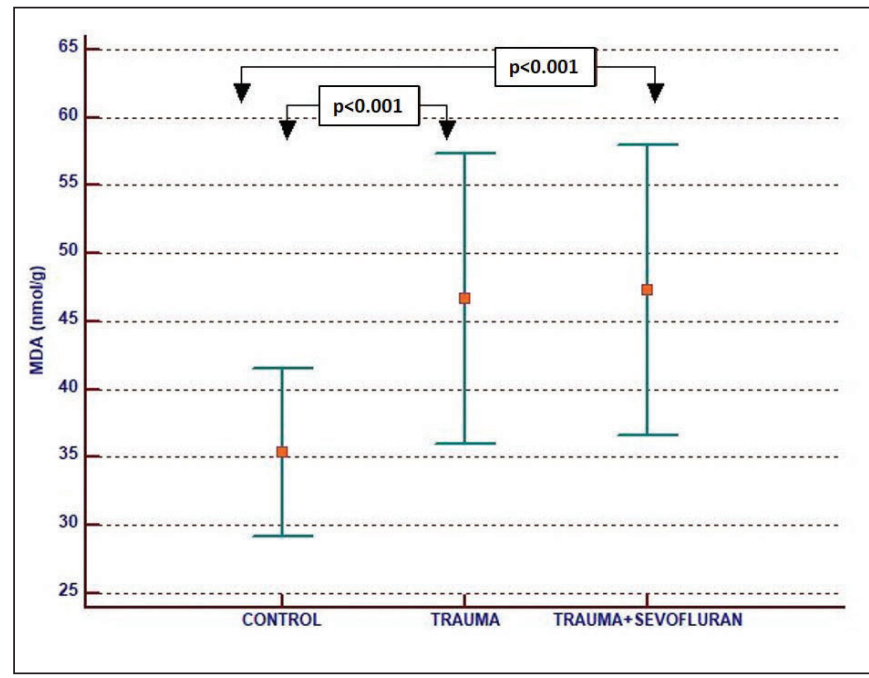

Figure 1: Malondialtehycle (MDA) values of all groups.

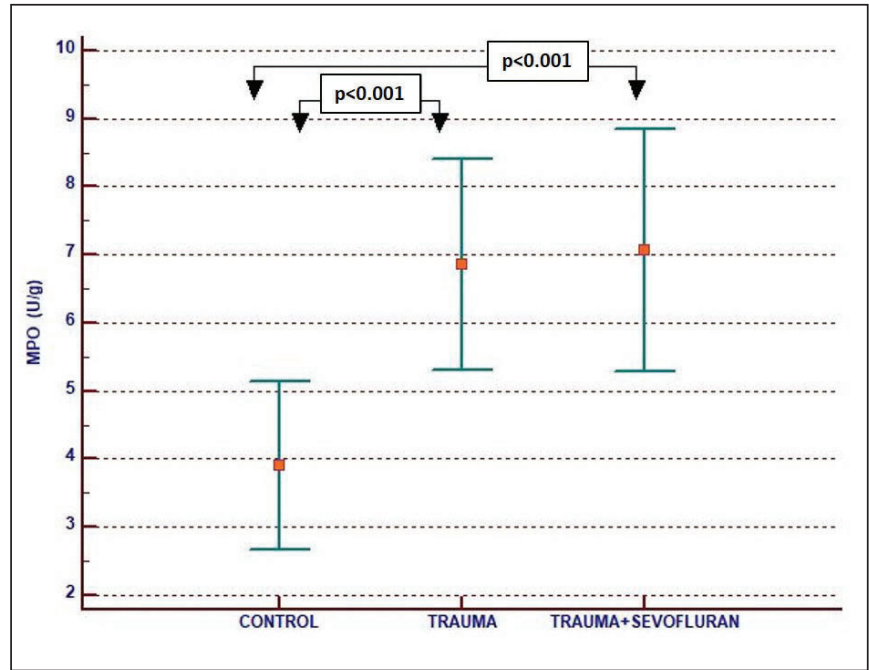

Figure 2: Myeloperoxidase (MPO) values of all groups.

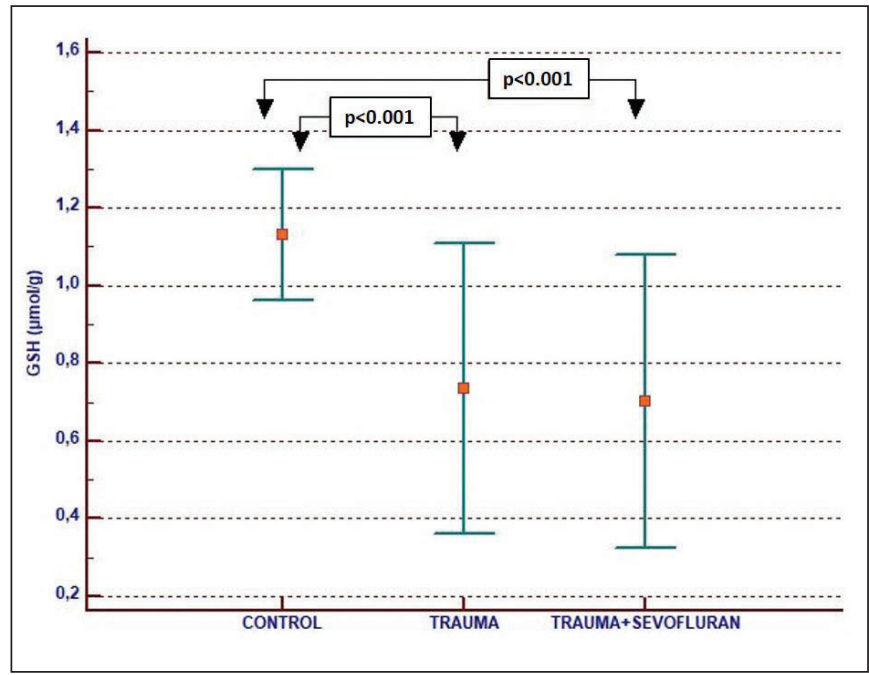

Figure 3: Glutathione (GSH) values of all groups. 
Dogan G. and Karaca O: Neuroprotective Effect of Sevoflurane

Table I: Biochemical Results Relevant to the Study Groups

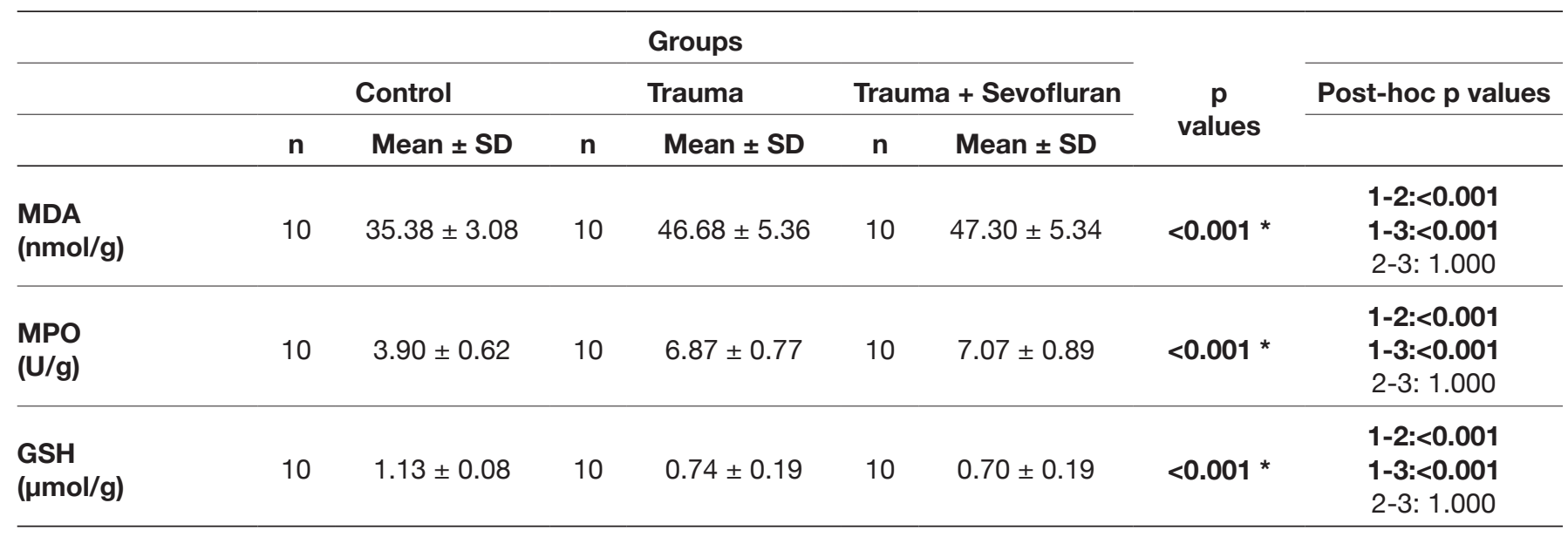

* Significant difference in $p<0.05$ level with One-Way ANOVA

GSH: glutathione, MDA: malondialdehyde, MPO: myeloperoxidase.
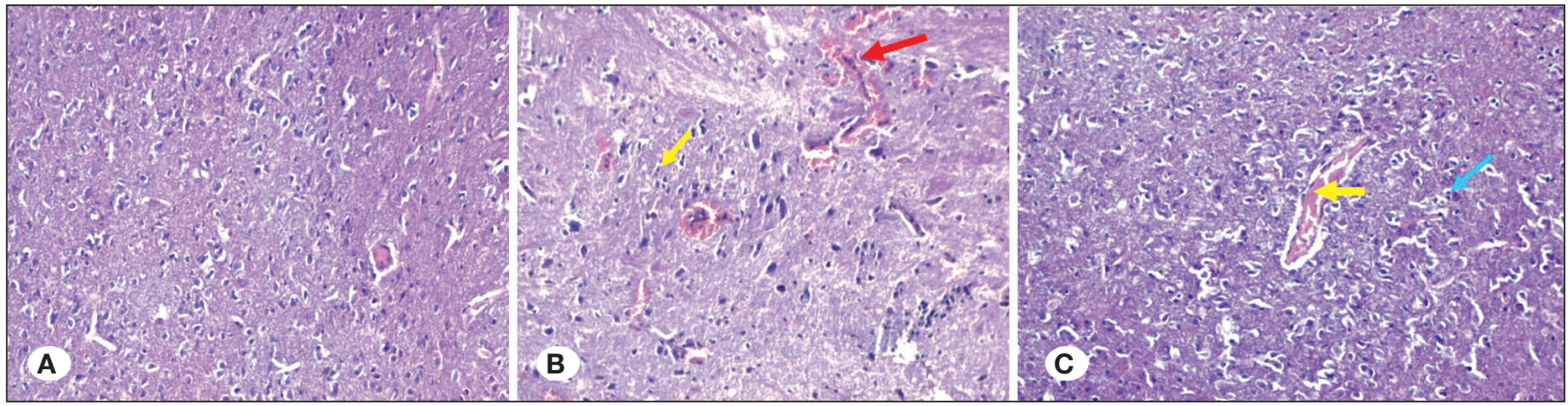

Figure 4: A) Control group: Normal appearance of neurons and glial cells in brain cortex. B) Trauma group: Picnosis in nucleus of neuron cells, degeneration in some neurons and glia cells (yellow arrow), dilatation and congestion in blood vessels (red arrow) C)Trauma+sevoflurane group: Degenerative changes in neurons and glial cells, vascular enlargement and congestion (yellow arrow), inflammatory cell infiltration around the blood vessels (blue arrow) (Haematoxylin and Eosin, 40x).

\section{Immunohistochemical Findings}

In the cerebellar sections of Group 1, cortical capillary endothelial and glial cells showed a positive VEGF expression (Figure 5A). Group 2 had clearly elevated VEGF expression in glial cells as well as vascular endothelial and inflammatory cells in the proximity of degenerated neurons (Figure 5B). Group 3 showed positive expression of VEGF in vascular endothelial and inflammatory cells (Figure 5C). In group 1, weak TNF-a expression was observed in glial cells located around small blood vessels in the cerebral cortex, whereas negative TNF-a expression was observed in neurons and other glial cells. In Group 2, TNF-a expression increased in glial cells and pyramidal neurons located around blood vessels. Histopathological sections of Group 3 revealed positive TNF-a expression in neurons with small granular and glial cells located around enlarged blood vessels. In Group 1, negative Bax expression was observed in neurons as well as granular and glial cells in the cerebral cortex. In Group 2, an intense Bax expression was observed in the outer membranes of degenerative neurons and glial cells. A positive reaction was also seen in endothelial cells and surrounding inflammatory cells. In Group 3, neurons and glial cells were nucleiabsent with positive Bax expression. The Bax reaction in Group 3 was significant in glial, blood vessel endothelial, and some inflammatory cells.

\section{DISCUSSION}

$\mathrm{TBI}$ sometimes causes the breakdown of the integrity of the blood-brain barrier and interaction between neurons and vascular structures. This may lead to leakages from vessels, high numbers of edematous areas, hemorrhage, and hypoxia. In severe conditions, it may result in cell death within the meninges and brain parenchyma. In these cases, axons can stretch and tear; further, there is disruption of communication between white and gray matter (1). Shortly after injury, sufficient amount of blood cannot be supplied to the areas and neurons undergoing necrosis. Moreover, greater loss of apoptotic neurons may occur after secondary hypoxia/ ischemia injury of oxidative stress and inflammation $(3,4,9)$. 

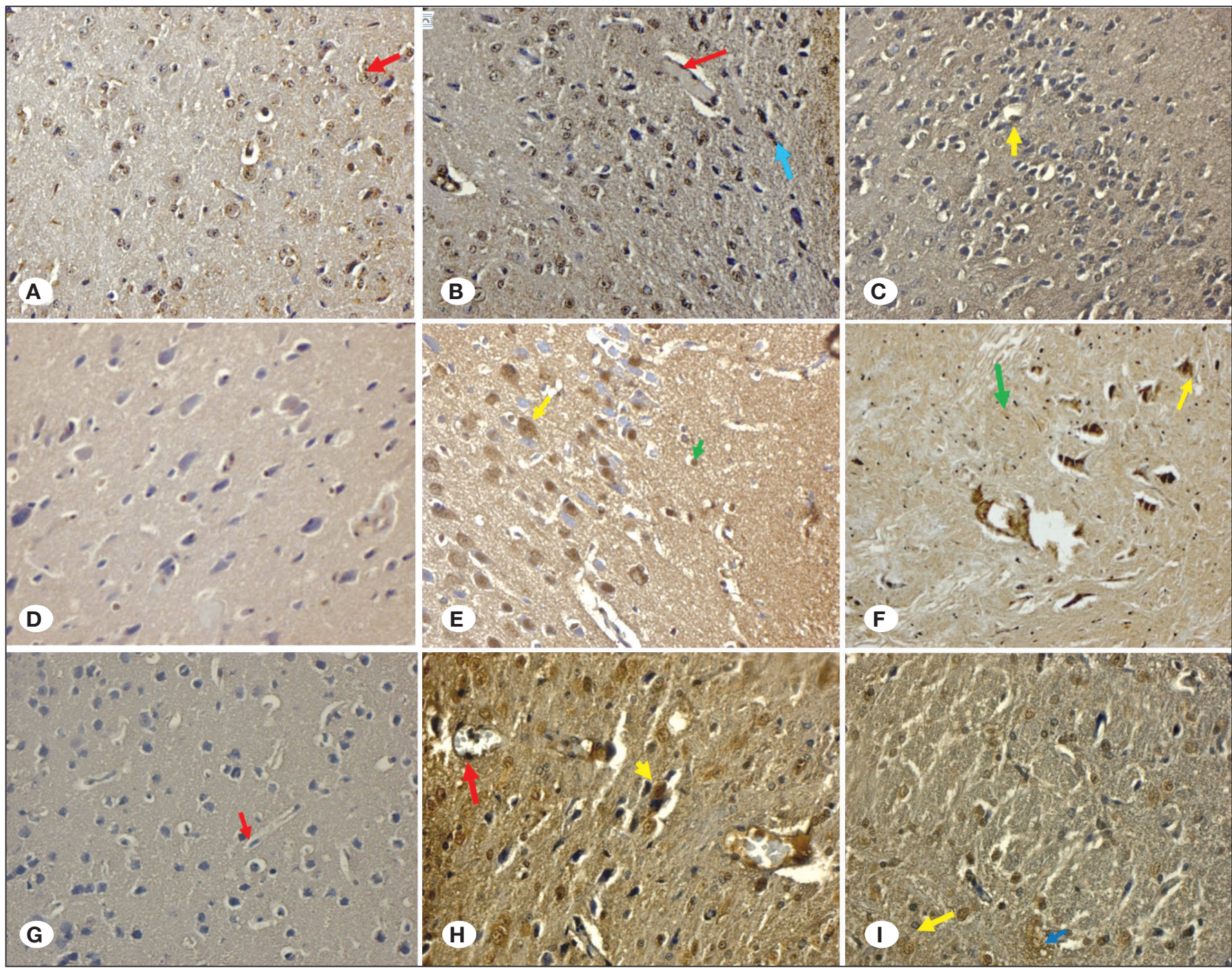

Figure 5: A) Control group: VEGF expression in the capillary endothelial (red arrow), and some glial cells of brain cortex, VEGF immunostaining original magnification $\times 40$, B) Trauma group: An increase in VEGF expression in dilated capillary endothelial cells (red arrow), vascular inflammatory cells and glial cells around some degenerated neurons (blue arrow), VEGF immunostaining original magnification $\times 40$. C) Trauma+sevofluran group: Positive VEGF expression in endothelial cells (red arrow) and inflammatory cells around the blood vessels, VEGF immunostaining original magnification $\times 40$. D) Control group: Weak TNF-a expression was observed in some glial cells around the small blood vessels in the cerebral cortex (green arrow), TNF-a immunostaining original magnification $\times 40$. E) Trauma group: An increase in TNF-a expression in glial cells (green arrow) and pyramidal neurons (yellow arrow) around the blood vessels, TNF-a immunostaining original magnification $\times 40$. F) Trauma+sevofluran group: Positive TNF-a expression in neurons (yellow arrow), small granular cells and glial cells (green arrow) around the blood vessels. TNF-a immunostaining original magnification $\times 40$. G) Control group: Negative Bax expression in neurons, granular and glial cells. Bax immunostaining original magnification $\times 40$. $\mathbf{H}$ ) Trauma group: An increase Bax expression in the outer membranes of degenerative neurons (yellow arrow) and glial cells. Bax immunostaining original magnification $\times 40$. I) Trauma+sevofluran group: Loss of nuclei of some neurons (yellow arrow) and glial cells with positive Bax reaction. Also the expression was seen in blood vessel endothelial and some inflammatory cells (blue arrow), Bax immunostaining original magnification $\times 40$.

Researchers showed that secondary brain injury after TBI may be induced by many factors such as oxidative stress, inflammation, and apoptosis. However, decreasing oxidative stress level and blocking inflammatory response may significantly reduce the duration of secondary trauma from TBI (10).
The use of sevoflurane at a concentration of $2 \%$ in neonatal and adult rats for 1 hour (short duration) causes neuroapoptosis and neurocognitive dysfunction (14). Li et al. showed protection effects of sevoflurane against cerebral ischemic injury through an antiapoptotic signaling pathway (17). As a result of these studies, inhibition of memory retention in oxidative injury has shown a causal link between sevoflurane 
inhalation and regulation of apoptotic and antiapoptotic gene expression.

VEGF is an angiogenic factor that triggers endothelial cell proliferation, angiogenesis and elevation of vascular permeability. This early stage of brain edema formation in brain injury involves the increase of VEGF. This may lead to further deterioration of the blood-brain barrier leading to neuronal dysfunction (22).

In a study on a TBI model, Krum and Khaibullina showed that the inhibition of VEGF signals, including VEGF receptor-1, inhibits the activity of reactive astrocytes and glial scar formation (16). After TBI, elevated VEGF levels, increased vascular permeability, and interaction of endothelial VEGF receptors lead to edematous vascular wall.

In one study, it has been shown that the deterioration of blood-brain barrier function in endothelial cells is improved by sevoflurane postconditioning. It has been reported that this anesthetic acts on tight and adherent intersections, possibly by decreasing the production of VEGF due to injury (26). In our study, increased VEGF expression in blood vessels, endothelial cells, glial cells, and inflammatory cells was observed after trauma (Figure 2B). However, VEGF expression did not change with the addition of sevoflurane treatment after an induced trauma (Figure 2C).

TBI initiates a neuroinflammatory cascade characterized by microglial activation and increased production of proinflammatory cytokines (23).

TNF-a is a pleiotropic cytokine that plays an important role in the immune and inflammatory activities of the brain. The brain begins producing TNF-a during infectious conditions through viruses, bacteria, ischemia, and trauma. Active microglia are a good indicator of brain inflammation (33). Uncontrolled inflammation is associated with microglial activation and has been documented to be harmful in neurogenesis, partly through the production of TNF-a $(7,19)$. Scherbel et al. reported that TNF-a causes a decrease in memory and neuromotor function in the post-traumatic period. It has been shown that TNF-a causes the expression of proadhesive molecules on the endothelium, leading to leukocyte accumulation, adhesion, and migration from capillaries to the brain. In addition, TNF-a activates glial cells, so that it regulates tissue remodeling, gliosis, and wound formation (3). In our study, TNF-a activity was found to increase apoptosis in glial cells and neurons secondary to increased inflammation around blood vessels from the induced trauma (Figure 2E). Sevoflurane treatment did not produce any change in cytokine activity after trauma (Figure 2F).

Bax is a protein involved in cell death and suppression of tumorigenesis. Bax is a proapoptotic protein, which controls the integrity of the mitochondrial outer membrane (29). Some neurons in the sevoflurane treatment group showed apoptosis due to a loss of the nucleus in which the proapoptotic stage progresses. However, not all neuron outer membranes showed Bax positive expression. Positive Bax expression was observed in glial cells, blood vessel endothelial cells, and some inflammatory cells. (Figure $2 \mathrm{H}, \mathrm{I}$ ).
It has been shown that oxidative stress and inflammation induce apoptosis after trauma and increase proapoptotic protein Bax activity. Shan et al. reported that prenatal exposure to $3 \%$ sevoflurane for 4 hours in rats increases apoptosis and axonal injury, which may lead to longterm learning and memory dysfunction (27). Tian et al. reported that sevoflurane exacerbates cognitive impairment induced by amyloid $\beta$-protein (A $\beta$ ) 1-40 in rats by initiating neurotoxicity, neuroinflammation, and neuronal apoptosis in rat hippocampus (30). Recently, He et al. showed that sevoflurane postconditioning weaken TBI-induced neuronal apoptosis by regulating autophagy via the PI3K/AKT signaling pathway (12). Contrarily, our study showed that sevoflurane administration in the acute period did not prevent oxidative stress, inflammation, and apoptosis.

\section{CONCLUSION}

Sevoflurane administration in the acute period of experimental TBI model did not prevent the development of oxidative stress, inflammation, and apoptosis in the brain. However, it may be effective in the chronic phase of TBI. Further experimental studies are needed to clarify the late effects of sevoflurane in TBI.

\section{ACKNOWLEDGEMENT}

We thank Engin Deveci from the Department of Histology and Embryology, Faculty of Medicine, Dicle University, Diyarbakır for assistance with histological evaluation. In addition, we thank Yasin Kenesari from the Department of Medical Biochemistry, Sungurlu State Hospital, Corum for his assistance in biochemical evaluations. Finally, we thank Emre Demir from the Department of Biostatistics, Hitit University, Corum for statistical analysis.

\section{REFERENCES}

1. Blennow K, Hardy J, Zetterberg H: The neuropathology and neurobiology of traumatic brain injury. Neuron 76(5):886-899, 2012

2. Cheong CU, Chang CP, Chao CM, Cheng BC, Yang CZ, Chio CC: Etanercept attenuates traumatic brain injury in rats by reducing brain TNF- a contents and by stimulating newly formed neurogenesis. Mediators Inflamm 14(1):33, 2013

3. Coles JP: Regional ischemia after head injury. Curr Opin Crit Care 10(2):120-125, 2004

4. Diaz-Arrastia R, Kochanek PM, Bergold P, Kenney K, Marx CE, Grimes CJ, Loh LT, Adam LT, Oskvig D, Curley KC, Salzer W: Pharmacotherapy of traumatic brain injury: State of the science and the road forward: Report of the Department of Defense Neurotrauma Pharmacology Workgroup. J Neurotrauma 31(2):135-158, 2014

5. Dogan G, Ipek H, Bas Y, Dogan G, Kayir S: Experimental study on prophylactic effects of vardenafil in ischemia-reperfusion model with intestinal volvulus injury in rats. J Pediatr Surg 2019 (Epub ahead of print)

6. Draper $\mathrm{HH}$, Hadley $\mathrm{M}$ : Malondialdehyde determination as index of lipid peroxidation. Methods Enzymol 186:421-431, 1990 
7. Ekdahl CT, Claasen JH, Bonde S, Kokaia Z, Lindvall O: Inflammation is detrimental for neurogenesis in adult brain. Proc Natl Acad Sci U S A 100(23):13632-13637, 2003

8. Feuerstein GZ, Liu T, Barone FC: Cytokines, inflammation, and brain injury: Role of tumor necrosis factor-alpha. Serebrovasc Brain Metab Rev 6(4):341-360,1994

9. Greve MW, Zink BJ: Pathophysiology of traumatic brain injury. Mt Sinai J Med 76(2):97-104, 2009

10. Gyoneva S, Ransohoff RM: Inflammatory reaction after traumatic brain injury: Therapeutic potential of targeting cellcell communication by chemokines. Trends Pharmacol Sci 36(7):471-480, 2015

11. Hall ED, Vaishnav RA, Mustafa AG: Antioxidant therapies for traumatic brain injury. Neurotherapeutics 7(1):51-61, 2010

12. He H, Liu W, Zhou Y, Liu Y, Weng P, Li Y, Fu H: Sevoflurane post-conditioning attenuates traumatic brain injury-induced neuronal apoptosis by promoting autophagy via the PI3K/AKT signaling pathway. Drug Des Devel Ther 12:629-638, 2018

13. Hillegass LM, Griswold DE, Brickson B, Albrightson-Winslow C: Assessment of myeloperoxidase activity in whole rat kidney. J Pharmacol Methods 24(4):285-295, 1990

14. Huang H, Liu CM, Sun J, Jin WJ, Wu YQ, Chen J: Repeated $2 \%$ sevoflurane administration in 7 and 60-day-old rats: Neurotoxicity and neurocognitive dysfunction. Anaesthesist 66(11):850-857, 2017

15. Keles GC, Cetinkaya BO, Eroglu C, Simsek SB, Kahraman H: Vascular endothelial growth factor expression levels of gingiva in gingivitis and periodontitis patients with/without diabetes mellitus. Inflamm Res 59(7):543-549, 2010

16. Krum JM, Khaibullina A: Inhibition of endogenous VEGF impedes revascularization and astroglial proliferation: Roles for VEGF in brain repair. Exp Neurol 181(2):241-257, 2003

17. Li X, Luo P, Wang F, Yang Q, Li Y, Zhao M, Wang S, Wang $\mathrm{Q}$, Xiong L: Inhibition of N-myc downstream-regulated gene-2 is involved in astrocyte-specific neuroprotection induced by sevoflurane preconditioning. Anesthesiology 121(3):549-562, 2014

18. Lim SW, Wang CC, Wang YH, Chio CC, Niu KC, Kuo JR: Microglial activation induced by traumatic brain injury is suppressed by postinjury treatment with hyperbaric oxygen therapy. J Surg Res 184(2):1076-1084, 2013

19. Liu YP, Lin HI, Tzeng SF: Tumor necrosis factor-a and interleukin-18 modulate neuronal cell fate in embryonic neural progenitor culture. Brain Res 1054(2):152-158, 2005

20. Marmarou A, Foda MA, van den Brink W, Campbell J, Kita $H$, Demetriadou K: A new model of diffuse brain injury in rats. Part I: Pathophysiology and biomechanics. J Neurosurg 80(2):291-300,1994

21. McCoy MK, Tansey MG: TNF signaling inhibition in the CNS: Implications for normal brain function and neurodegenerative disease. J Neuroinflammation 5:45, 2008
22. Obermeier B, Daneman R, Ransohoff RM: Development, maintenance, and disruption of the blood-brain barrier. Nat Med 19(12):1584-1596, 2013

23. Ozevren H, Irtegun Kandemir S, Deveci E, OE M, Deveci S: Neuroprotective effects of potentilla fulgens on traumatic brain injury in rats. Anal Quant Cytol Histol 39(1):35-45, 2017

24. Paglia DE, Valentine WN: Studies on the quantitative and qualitative characterization of erythrocyte glutathione peroxidase. J Lab Clin Med 70(1):158-169, 1967

25. Raghupathi R, Graham DI, Mclntosh TK: Apoptosis after traumatic brain injury. J Neurotrauma 47(5):781-785, 2016

26. Restin T, Kajdi ME, Schläpfer M, Roth Z'graggen B, Booy C, Dumrese C, Beck-Schimmer B: Sevoflurane protects rat brain endothelial barrier structure and function after hypoxiareoxygenation injury. Plos One 12(10):e0184973, 2017

27. Shan $\mathrm{Y}$, Yang $\mathrm{F}$, Tang $\mathrm{Z}$, Bi C, Sun S, Zhang Y, Liu H: Dexmedetomidine ameliorates the neurotoxicity of sevoflurane on the immature brain through the BMP/SMAD signaling pathway. Front Neurosci 12:964, 2018

28. Shohami E, Gallily R, Mechoulam R, Bass R, Ben-Hur T: Cytokine production in the brain following closed head injury: Dexanabinol (HU-211) is a novel TNF-alpha inhibitor and an effective neuroprotectant. J Neuroimmunol 72(2):169-177, 1997

29. Solaroglu I, Tsubokawa T, Cahill J, Zhang JH: Anti-apoptotic effect of a granulocyte-colony stimulating factor after focal cerebral ischemia in the rat. Neuroscience 143:965-974, 2006

30. Tian Y, Chen KY, Liu LD, Dong YX, Zhao P, Guo SB: Sevoflurane exacerbates cognitive impairment inducedby $A \beta 1-40$ in rats through initiating neurotoxicity, neuroinflammation, and neuronal apoptosis in rat hippocampus. Mediators Inflamm 2018:3802324, 2018

31. Ucar T, Tanriover G, Gurer I, Onal MZ, Kazan S: Modified experimental mild traumatic brain injury model. J Trauma 60(3):558-565, 2006.

32. Werner C, Engelhard K: Pathophysiology of traumatic brain injury. Br J Anaesth 99(1):4-9, 2007

33. Whitney NP, Eidem TM, Peng H, Huang Y, Zheng JC: Inflammation mediates varying effects in neurogenesis: Relevance to the pathogenesis of brain injury and neurodegenerative disorders. J Neurochem 108(6):13431359, 2009

34. Yamamoto K, Yamamoto E, Sugimoto T, Sagakami T, Yamatodani A: Sevoflurane-induced pica in female rats. $J$ Pharmacol Sci 131(1):68-71, 2016

35. Zhang P, Yang PL, Sun XX, Zhu T, Ye L: Emulsified sevoflurane selectively blocking spinal cord and brain in rabbit model. Sichuan Da Xue Xue Bao Yi Xue Ban 47(5):781-785, 2016 